\title{
Precancerous Lesions of the Cervix and Associated Factors among Women of East Gojjam, Northwest Ethiopia, 2020
}

\author{
Mamaru Getinet' \\ Molla Taye ${ }^{2}$ \\ Abebe Ayinalem ${ }^{2}$ \\ Menberesibhat Gitie ${ }^{2}$ \\ 'Department of Biomedical Sciences, \\ College of Medicine and Health Sciences, \\ Debre Markos University, Debre Markos, \\ Ethiopia; ${ }^{2}$ Department of Human \\ Anatomy, College of Medicine and Health \\ Sciences, University of Gondar, Gondar, \\ Ethiopia
}

Background: Cervical cancer is the commonest cancer of women's reproductive system, and is caused by a progression of precancerous lesions of the cervix. Studies on the prevalence and associated factors of precancerous lesions of the cervix are very limited in Ethiopia, particularly in the study area.

Objective: This study aimed to assess precancerous lesions of the cervix and associated factors among women of East Gojjam, northwest Ethiopia in 2020.

Methods: A facility-based cross-sectional study was conducted on 340 cervical cancerscreened women in three hospitals of East Gojjam from February to April 2020. Data were collected by six BSc-qualified nurses who were working in the selected hospitals. EpiData Manager and SPSS 26 were used for data management and analysis. After the data had been clean, descriptive analysis was done and multivariate logistic regression used to identify predictors of precancerous lesions of the cervix. Statistical significance was taken to be $P<0.05$.

Results: Of the 340 recruited women, $15.3 \%$ (95\% CI 11.83\%-19.54\%) had precancerous cervical lesions. Mean age was 37.11 \pm 9.3 years. Age 46-55 (AOR 3.8, 95\% CI 1.21-12.47) years, age 56-65 (AOR 12.26, 95\% CI 3.18-47.18) years, residing rurally (AOR 2.04, 95\% CI 1.12-3.7), prolonged use of oral contraceptive pills (AOR 9.11, 95\% CI 1.14-72.8), history of sexual transmitted infection (STI; AOR 3.40, 95\% CI 1.32-8.78), HIV-positive status (AOR $4.89,95 \%$ CI 1.54-15.49), and number of lifetime sexual partners (AOR 9.87, 95\% CI 1.3870.4) were important factors associated with precancerous lesions of the cervix.

Conclusion: We found relatively high prevalence of precancerous cervical lesions. Age, rural residence, prolonged use of oral contraceptives, STI, multiple sexual partners, and being HIV-positive were important factors associated with precancerous cervical lesions. Women aged $>46$ years, with a history of STI, being HIV infected, and with a history of multiple sexual partners should be encouraged to get screened for cervical cancer.

Keywords: visual inspection after acetic acid, precancerous lesions of cervix, cervical cancer, East Gojam Zone

\section{Introduction}

The cervix is the narrow or constricted inferior portion of the uterus, part of which projects into the vagina. The cervix differs histologically from the rest of the uterus. The endocervical mucosa is lined with a simple columnar epithelium on a thick lamina propria containing many large, branched, mucus-secreting cervical glands. The cervical region around the external os projects slightly into the upper vagina and is covered by the exocervical mucosa with unkeratinized stratified glycogen containing squamous epithelium continuous with that of the vagina. ${ }^{1}$ The junction
Correspondence: Mamaru Getinet Department of Biomedical Sciences, College of Medicine and Health Sciences, Debre Markos University, PO Box 269,

Debre Markos, Ethiopia,

Tel +25I-93- |88-848|

Fax $+25 I 587780673$

Email ermy202699@yahoo.com;

getinetmamarul2@gmail.com 
between this squamous epithelium and the mucussecreting columnar epithelium of the endocervix occurs in the transformation zone, an area just outside the external os that shifts slightly with the cyclical changes in uterine size. Periodic exposure of the squamocolumnar junction (SCJ) to the vaginal environment can stimulate the reprogramming of epithelial stem cells, which occasionally leads to intraepithelial neoplasia. ${ }^{2}$

Cancer is defined as malignant, autonomous, uncontrolled growth and division of cells. Cervical cancer is the most common cancer of a woman's reproductive system, and is preceded by a long phase of preinvasive disease, characterized microscopically as a spectrum of precancerous cervical lesions. ${ }^{3}$ Precancerous lesions of the cervix are abnormal cellular changes located around the cervix that start in the cells on the surface of the cervix near the SCJ. The lesions may gradually progress to cervical cancer unless screened and treated early. Under microscopic examination, about $80 \%-90 \%$ of cervical cancers are squamous-cell cancers, and the remaining 10\%-20\% arise from mucous-producing cervical gland cells. ${ }^{4}$

Moreover, cervical intraepithelial neoplasia's (CIN) are abnormal cytological and histological differentiation characterized by disrupted architecture of the epithelium, increased mitotic activities, presence of an atypical nucleus, and cellular size variability. ${ }^{5}$ Histologically precancerous lesions of the cervix are graded into CIN1, CIN2, and CIN3, signifying lesions invading the lower third, middle third, and upper third of the epithelium, respectively. ${ }^{4}$ Of the three stages CIN2 and CIN3 are highgrade cancer precursors that have a higher probability of progression to invasive cancer. ${ }^{6}$

Unlike other reproductive-organ cancers, cervical cancer can be preventable through early identification of its precancerous lesions with screening and treatment of lesions. Such lesions can be identified by one of three methods: Pap smear, visual inspection with acetic acid (VIA), and human papillomavirus (HPV) DNA test. In developing countries with limited access to the Pap smear, VIA is the most widely implemented earlydetection method. $^{7}$ A positive VIA test shows a welldefined acetowhitish area formation 1 minute after the application of acetic acid on the cervix. ${ }^{4}$

Nowadays, cervical cancer is a global health problem, and a majority $(80 \%)$ of new cases are found in developing countries. ${ }^{8}$ In sub-Saharan Africa, there is a lack of information about cervical cancer screening and prevention services, causing late-stage detection. Therefore, late- stage disease is associated with low survival rates after surgery or radiotherapy. ${ }^{9}$ A sexually transmitted HPV is the main cause of cervical cancer; however, the sole existence of the virus may not be a guarantee of developing cervical cancer. As such, the coexistence of host factors that allow the transition from infection to cancer is necessary. Possible host factors are age, early commencementof sexual intercourse, multiparity, multiple sexual partners, oral contraceptive use, smoking, history of STI, and HIV. ${ }^{10}$

According to a 2018 estimate, there are about 570,000 cases of cervical cancer and 311,000 deaths from the disease annually worldwide. ${ }^{8}$ The current estimate shows that Ethiopia has 31.5 million women aged 15 years and older at risk of developing cervical cancer. Moreover, every year 6,294 women are diagnosed with cervical cancer and 4,884 die from the disease. ${ }^{11}$ A study conducted in Arba-Minch in southern Ethiopia showed that the prevalence of VIA-positive precancerous cervical lesions was $27.7 \%$, which is relatively high. ${ }^{12}$ Despite this fact, national screening coverage for cervical cancer is very low $(0.8 \%) .{ }^{11}$ Furthermore, in Ethiopia, early sexual practice, high prevalence of HIV, and low socioeconomic status may predispose women to cervical cancer. Lack of funds for screening services, low awareness of screening, and a shortage of trained health professionals are also the main challenges in performing cervical cancer screening and treatment programs. ${ }^{7}$

To manage the burden of cervical cancer, improved screening coverage, availability of vaccination, early treatment of cervical lesions, identification, and monitoring of the risk factors are worthy. In a resource-poor setting, the aforementioned strategies have a profoundly positive effect in reducing the mortality and morbidity caused by cervical cancer. ${ }^{13,14}$ As of September 2010, Ethiopia had implemented these strategies, with prevention and control of cervical cancer also becoming part of the national health agenda. ${ }^{7}$ Despite the implementation of such strategies, based on a literature search, data on the prevalence and risk factors of precancerous lesions of the cervix in this study setting were sparse at the time of writing. As such, the goal of the present study was to assess the prevalence of precancerous lesions of the cervix and associated factors among women attending cervical cancerscreening services in primary and referral hospitals of East Gojjam, northwest Ethiopia. This study helps in guiding health authorities in terms of planning and intervention strategies like health education and promotion of cervical precancerous lesions care activities. This may strengthen 
existing cervical cancer prevention and control programs. The findings of this study will also be used as baseline data for further studies.

\section{Methods}

A facility-based cross-sectional study design was conducted at three public hospitals in East Gojjam from February to April 2020. The sample size was calculated using a single population-proportion formula $\left(\mathrm{n}=\frac{(\mathrm{Za} / 2)^{2} \mathrm{P}(1-\mathrm{P})}{\mathrm{D}^{2}}\right)$ considering the proportion of precancerous cervical lesions in ArbaMinch health institutions of $27.7 \%$, with a $95 \% \mathrm{CI}$ and $5 \%$ margin of error. The final sample size became $340 .{ }^{12}$ Three hospitals (Debre Markos Referral Hospital, Bichena Primary Hospital, and Shegaw Motta Primary hospital) were selected from ten public hospitals (one referral and nine primary) based on a lottery method. All women who had been screened for cervical cancer in these hospitals were included until the sample size required was obtained. In this study, age, marital status, education, occupation, religion, residence, contraceptive use, age at menarche, menstrual history, age at first full-term delivery, parity, history of abortion, age at first sex, lifetime sexual partners of the women, lifetime sexual partners of the husband, age at first marriage, condom use, history of STI, history of HIV infection, WHO stage of HIV, antiretroviral therapy initiation, CD4 count, history of smoking and alcohol use were the variables analyzed for association with the development of precancerous cervical lesions.

\section{Data Collection and Quality Assurance}

Data were collected using a pretested structured questionnaire prepared by reviewing related studies, with modifications in line with the objectives of this particular study. ${ }^{12,15-17}$ Two days of training on data-collection procedures was given for data collectors. Six BSc-qualified nurses certified in cervical screening and working in the gynecology ward in selected hospitals were assigned to collect the data, and the principal investigator supervised data collection. The questionnaire was first prepared in English and then translated into Amharic. Data were collected from the clients through face-to-face interviews at the health facility after getting verbal consent. Screening was performed by a trained professional as per the cervical cancer-screening protocol described in the guidelines. ${ }^{7}$

Before the commencement of data collection, 2 days of training focused on the data-collection tool and procedure was given to the data collectors provided. The questionnaire was pretested on 17 women attending cervical cancer services at
Debre Work Primary Hospital to ensure its consistency, completeness, and appropriate modifications before the actual data collection. The principal investigator carried out site supervision weekly during the whole data-collection period to monitor data collection. The collected data were checked for completeness and consistency by the principal investigator.

\section{Data Processing and Analysis}

Data collected were first coded, entered, and cleaned using EpiData 4.6, then exported to SPSS 26 for analysis. Percentages, summary statistics, and cross-tabulation were used to summarize sociodemographic variables and the prevalence of precancerous lesions of the cervix. In order to assess the association of risk factors with precancerous lesions of the cervix, bivariate and multivariate logistic regression was employed. Those variables yielding $P<0.25$ on bivariate logistic regression were reanalyzed using multivariate logistic regression. On multivariate logistic regression, those variables yielding $P<0.05$ were considered statistically significant factors associated with the presence of precancerous lesions of the cervix.

\section{Ethics Approval}

The study was approved by the ethics committee of the School of Medicine, College of Medicine and Health Science, University of Gondar (1874/02/2020). Permission letters were also obtained from the East Gojjam Zone Health Department and managers of the selected hospitals. The study was conducted in compliance with the Declaration of Helsinki. Study participants were approached during their hospital visits and asked to participate. Informed written consent was obtained from participants after being informed about the voluntary basis of participation. All methods used in the study were in line with the regulations and guidelines for treatment of diseases in referral hospitals of East Gojjam. The confidentiality of patients' information was protected.

\section{Measurements and Definitions}

Acetowhitish: white area on the cervix after application of $5 \%$ acetic acid, indicating possible precancerous lesions. ${ }^{14}$

Precancerous lesions of the cervix: dense acetowhite lesions with well-defined margins observed within the transformation zone originating from the SCJ, or if the whole cervix or cervical growth turns white.

Contraceptive use: use of such contraceptive methods such as oral contraceptive pills or an injectable, implant, and intrauterine device (IUD) $\geq 1$ month. 
Early initiation of sex: sexual practice before the age of 18 years.

Multiparity: having borne more than two children.

Multiple sexual partners: engaging in sexual activities with two or more people within a specific period.

Negative on VIA: no acetowhite lesions, indicating a normal cervix remaining pale and pink. ${ }^{14}$

Positive on VIA: sharp, distinct, well-defined, dense acetowhitish areas close to the SCJ. ${ }^{14}$

\section{Results}

\section{Sociodemographic Characteristics}

A total of 340 women aged 25-65 years were screened for cervical cancer by VIA from February to April 2020. The response rate was $100 \%$. Among the participants, 164 (48.2\%) were aged $25-35$ years (mean $37.11 \pm 9.3$ years), 317 (93.2\%) were Orthodox Christians, followed by Muslims, 331 were Amhara (97.4\%), followed by Oromo $(9,2.6 \%)$, residing rurally $(40.9 \%), 249(73.2 \%)$ were married, 192 (56.5\%) were housewives, and 135 (39.7\%) had had no formal education (Table 1).

\section{Reproductive Health Characteristics}

In sum, $232(68.2 \%)$ of the subjects used contraception: 26 (11.4\%), 63 (27.1\%), 92 (39.6\%), and 51 (21.9\%) IUDs, implants, injectables, and pills, respectively. Regarding duration of use, $132(56.9 \%)$ had been using contraception $\geq 5$ years. A majority $(176,51.8 \%)$ had a regular menstrual history, 73 a history of postcoital bleeding, with the rest having no history of postcoital bleeding, 226 (66.5\%) had no history of pelvic infection, $272(80 \%)$ had given birth, 231 (84.9\%) had parity greater than or equal to two and $41(15.1 \%)$ fewer than two (overall mean 4.1 \pm 2.6$), 181$ (53.2\%) had had their first child aged $\geq 18$ years (mean $21 \pm 4.74$ years), and 243 (71.5\%) had no abortion history. Among those who had had abortions, seven $(7.2 \%)$ had had recurrent (more than three) abortions in their lifetime (Table 2).

\section{Lifestyle and Sexual Behavior}

Only $47(13.8 \%)$ subjects had ever been screened for cervical cancer. All who had been screened were negative result for precancerous cervical lesions. Regarding the time of screening, $37(78.3 \%)$ of respondents had been screened $>5$ years previously, while only ten $(21.3 \%)$ had been screened within the last 5 years. even $(2.1 \%)$ respondents had a history of smoking, 22 $(6.5 \%)$ drank alcohol frequently, 232 had their first
Table I Sociodemographic characteristics

\begin{tabular}{|c|c|c|c|}
\hline & $\mathbf{n}$ & $\%$ & $\begin{array}{c}\text { Mean } \pm \\
\text { SD }\end{array}$ \\
\hline Age, years & & & $37.11 \pm 9.3$ \\
\hline $25-34$ & 164 & 48.2 & \\
\hline $36-45$ & 117 & 34.4 & \\
\hline $46-55$ & 39 & 11.5 & \\
\hline $56-65$ & 20 & 5.9 & \\
\hline \multicolumn{4}{|l|}{ Religion } \\
\hline Orthodox & 317 & 93.2 & \\
\hline Muslim & 15 & 4.4 & \\
\hline Protestant & 8 & 2.4 & \\
\hline \multicolumn{4}{|l|}{ Ethnicity } \\
\hline Amhara & 331 & 97.4 & \\
\hline Oromo & 9 & 2.6 & \\
\hline \multicolumn{4}{|l|}{ Residence } \\
\hline Urban & 201 & 59.1 & \\
\hline Rural & 139 & 40.9 & \\
\hline \multicolumn{4}{|l|}{ Marital status } \\
\hline Married & 249 & 73.2 & \\
\hline Divorced & 42 & 12.4 & \\
\hline Single & 29 & 8.5 & \\
\hline Widowed & 20 & 5.9 & \\
\hline \multicolumn{4}{|l|}{ Education } \\
\hline Diploma and higher & 66 & 19.4 & \\
\hline Secondary $(9-12)$ & 53 & 15.6 & \\
\hline Primary (I-8) & 86 & 25.3 & \\
\hline None & 135 & 39.7 & \\
\hline \multicolumn{4}{|l|}{ Occupation } \\
\hline Housewife & 192 & 56.5 & \\
\hline Government employee & 68 & 20 & \\
\hline Merchant & 43 & 12.6 & \\
\hline Daily laborer & 37 & 10.9 & \\
\hline
\end{tabular}

sexual intercourse aged $<18$ years and the rest $(108$, $31.8 \%) \geq 18$ years. The mean age of first sexual contact was $17.03 \pm 3.47$ years, while 185 were married aged $<18$ years, with mean age at first marriage 16.99 \pm 3.95 years.

As shown in Table 3, 268 (78.8\%) subjects had not ever used condoms, $106(31.2 \%)$ had a history of STI, and 115 (33.8\%) of them reported a history of STI in their husbands. A total of 264 (77.6\%) had been tested for HIV, of whom 54 (15.9\%) were HIV-positive (all on antiretroviraltherapy, 171 respondents had had more than two sexual partners, with the rest $(169,49.7 \%)$ having had just one.

\section{Prevalence of Precancerous Cervical Lesions}

The prevalence of precancerous cervical lesions among women screened for cervical cancer was 52 (15.3\%, 95\% CI $11.83 \%-19.54 \%$; Figure 1). 
Table 2 Reproduction-related characteristics

\begin{tabular}{|c|c|c|c|}
\hline & $\mathbf{n}$ & $\%$ & Mean \pm SD \\
\hline \multicolumn{4}{|l|}{ Contraceptive use } \\
\hline No & 108 & 31.7 & \\
\hline Yes & 232 & 68.2 & \\
\hline \multicolumn{4}{|l|}{ Type of contraceptive } \\
\hline Injectable & 92 & 39.6 & \\
\hline Implant & 63 & 27.1 & \\
\hline Pills & 51 & 21.9 & \\
\hline IUD & 26 & 11.4 & \\
\hline \multicolumn{4}{|l|}{$\begin{array}{l}\text { Duration of } \\
\text { contraceptive use, years }\end{array}$} \\
\hline$<5$ & 100 & 43.1 & \\
\hline$\geq 5$ & 132 & 56.9 & \\
\hline \multicolumn{4}{|l|}{ Menstrual history } \\
\hline Regular & 176 & 51.8 & \\
\hline Irregular & 151 & 44.4 & \\
\hline No menses & 13 & 3.8 & \\
\hline \multicolumn{4}{|l|}{ Postcoital bleeding } \\
\hline No & 267 & 78.5 & \\
\hline Yes & 73 & 21.5 & \\
\hline \multirow{2}{*}{\multicolumn{4}{|c|}{$\begin{array}{l}\text { History of pelvic } \\
\text { infection }\end{array}$}} \\
\hline & & & \\
\hline No & 226 & 66.5 & \\
\hline Yes & 114 & 33.5 & \\
\hline \multicolumn{4}{|l|}{ Parous } \\
\hline No & 68 & 20 & \\
\hline Yes & 272 & 80 & \\
\hline Number of births & & & $4.18 \pm 2.6$ \\
\hline$<2$ & 41 & 15.1 & \\
\hline$\geq 2$ & 231 & 84.9 & \\
\hline Age at first birth, years & & & $21 \pm 4.7$ \\
\hline$<18$ & 91 & 26.8 & \\
\hline$\geq 18$ & 181 & 53.2 & \\
\hline Number of abortions & & & $2 \pm 1.8$ \\
\hline$<3$ & 90 & 26.5 & \\
\hline$\geq 3$ & 7 & 7.2 & \\
\hline
\end{tabular}

\section{Factors Associated with Precancerous Lesions of the Cervix}

After bivariate analysis, variables yielding $P<0.25$ qualified as confounding factors, and these were reanalyzed on multivariate logistic regression to determine their association with precancerous lesions of the cervix. After this analysis, those yielding $P<0.05$ were deemed to be significantly associated with precancerous lesions of the cervix.

\section{Bivariate Logistic Regression}

On bivariate logistic regression analysis, ages 36-45 (COR 2.134, 95\% CI 0.913-4.986), 46-65 (COR 11.41, 95\% CI 4.61-28.29), and 56-65 (COR 31.4, 95\% CI 9.74-101.17) years, type of contraceptive (COR 5.41, 95\% CI 2.97-9.83),
Table 3 Lifestyle and sexual behavior characteristics

\begin{tabular}{|c|c|c|c|}
\hline & $\mathbf{n}$ & $\%$ & $\begin{array}{l}\text { Mean } \pm \\
\text { SD }\end{array}$ \\
\hline \multicolumn{4}{|l|}{$\begin{array}{l}\text { Previously screened for cervical } \\
\text { cancer }\end{array}$} \\
\hline No & 293 & 86.2 & \\
\hline Yes & 47 & 13.8 & \\
\hline \multicolumn{4}{|l|}{ Time of previous screening } \\
\hline Within 5 years & 37 & $78.7 \%$ & \\
\hline Before 5 years & 10 & $21.3 \%$ & \\
\hline \multicolumn{4}{|l|}{ History of smoking } \\
\hline No & 333 & 97.9 & \\
\hline Yes & 7 & 2.1 & \\
\hline \multicolumn{4}{|l|}{ History of drinking } \\
\hline No & 318 & 93.5 & \\
\hline Yes & 22 & 6.5 & \\
\hline Age at first marriage, years & & & $16.99 \pm 3.95$ \\
\hline$<18$ & 185 & 59.4 & \\
\hline$\geq 18$ & 123 & 39.6 & \\
\hline Age at first sex, years & & & $17.03 \pm 3.47$ \\
\hline$<18$ & 232 & 68.2 & \\
\hline$\geq 18$ & 108 & 31.8 & \\
\hline \multicolumn{4}{|l|}{ Condom use } \\
\hline Always & 4 & 1.2 & \\
\hline Sometimes & 68 & 20 & \\
\hline Never & 268 & 78.8 & \\
\hline \multicolumn{4}{|l|}{ History of STI } \\
\hline No & 234 & 68.8 & \\
\hline Yes & 106 & 31.2 & \\
\hline \multicolumn{4}{|l|}{ HIV status } \\
\hline Negative & 210 & 61.8 & \\
\hline Positive & 54 & 15.9 & \\
\hline Unknown & 76 & 22.3 & \\
\hline \multicolumn{4}{|l|}{ CD4 count, cells $/ \mathrm{mm}^{3}$} \\
\hline$<200$ & 10 & 18.5 & \\
\hline$\geq 200$ & 44 & 81.5 & \\
\hline $\begin{array}{l}\text { Lifetime sexual partners of the } \\
\text { women }\end{array}$ & & & $2.1 \pm 1.65$ \\
\hline$<2$ & 169 & 49.7 & \\
\hline$\geq 2$ & 171 & 50.3 & \\
\hline $\begin{array}{l}\text { Other lifetime sexual partners } \\
\text { (husband) }\end{array}$ & & & $2.8 \pm 1.6$ \\
\hline$<2$ & 153 & 44.9 & \\
\hline$\geq 2$ & 161 & 47.3 & \\
\hline
\end{tabular}

education (COR 2.05, 95\% CI 1.44-2.92), rural residence (COR 2.04, 95\% CI 1.12-3.7), parity (COR 7.43, 95\% CI 1.76-31.36), number of births (COR 1.845, 95\% CI0.893.8), history of abortions (COR 2.77, 95\% CI 1.51-5.09), history of pelvic infection (COR 2.27, 95\% CI 1.24-4.13), history of STI (COR 3.45, 95\% CI 1.88-6.33), partner's history of STI (COR 2.03, 95\% CI 1.12-3.70), 
The prevalence of precancerous cervical lesion

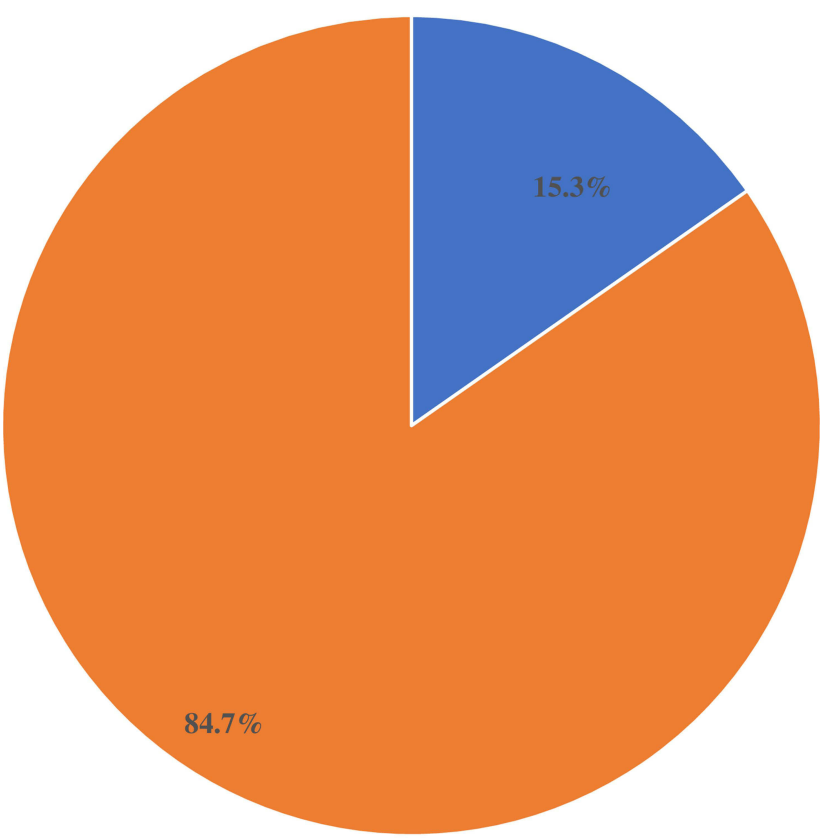

- VIA Positive

- VIA Negative

Figure I Prevalence of precancerous lesions of the cervix.

HIV-positive serostatus (COR 6.93, 95\% CI 3.42-14.04), two or more lifetime sexual partners (COR 9.95, 95\% CI 4.11-24.56), first sexual intercourse aged $>18$ years (COR $0.118,95 \%$ CI $0.034-0.411)$, and first birth aged $\geq 18$ years (COR 0.19, 95\% CI $0.1-0.36$ ) showed significant associations with precancerous cervical lesions.

\section{Multivariate Logistic Regression}

As shown in Table 4, after controlling for the effect of confounding factors, age, rural residence, using oral contraception, STI, HIV, and multiple sexual partners were found to be significantly associated with precancerous cervical lesions. Women aged $46-55$ and $56-65$ years were 3.8 times and 12.2 times as likely to have precancerous cervical lesions as those aged 25-35 years, respectively. Rural dwellers were 3.5 times as likely to develop precancerous cervical lesions as urban dwellers (AOR $3.524,95 \%$ CI $1.25-9.88$ ).

Regarding the type of contraceptive used, women on contraception were 9.1 times as likely to develop precancerous cervical lesions as IUD users (AOR 9.11, 95\% CI 1.14-72.8).
Women with a history of STI were 3.4 times as likely to have precancerous cervical lesions as those with no STI history (AOR 3.40, 95\% CI 1.32-8.78). Women who had HIVpositive serostatus were 4.9 times as likely to have precancerous cervical lesions as HIV-negatives (AOR 4.89, 95\% CI 1.54-15.49). Women who had had two and more lifetime sexual partners were 9.8 times as likely to develop precancerous cervical lesions as those who had had fewer than two sexual partners (AOR 9.87, 95\% CI 1.38-70.4).

\section{Discussion}

We found that the prevalence of precancerous cervical lesions was $15.3 \%$, lower than another study conducted in southern Ethiopia (27.7\%). ${ }^{12}$ This discrepancy may be due to differences in the test providers' skills and the study period. For instance, the study done in southern Ethiopia used 2 years' data, while we used only three months' data. However, the finding of the present study was higher than studies carried out in Bahir Dar, northwest Ethiopia $(14.3 \%),{ }^{18}$ Dessie, northeast Ethiopia (6.9\%), Madagascar $(11.3 \%),{ }^{19}$ and Malawi (12.4\%). ${ }^{19}$ This discrepancy may be due to differences in the age of study populations, the underlying prevalence of STI, and the high prevalence of HIV. However, it was lower than findings of studies done on HIVinfected women in Tanzania $(76 \%)^{20}$ and southern Ethiopia $(22.1 \%) .{ }^{21}$ This discrepancy may be due to differences in study population. Those studies from Tanzania and southern Ethiopia included only HIV-infected women as subjects, but we recruited both HIV-positive and -negative women as subjects.

The current study also assessed factors associated with precancerous cervical lesions, and the findings revealed that respondents aged 46-65 years, living rurally, having prolonged use of oral contraceptive pills, having a history of STI, living with HIV infection, and having two or more lifetime sexual partners were predictors of recancerous cervical lesions. The current study also illustrated that woman aged 46-55 and 56-65 years were 3.8 times and 12.2 times as likely to have precancerous cervical lesions as those aged $25-35$ years, respectively. This finding is consistent with a study done in Beijing, where age 46-55 years increased the prevalence of high-grade intraepithelial lesions of the cervix by 1.15 times compared with age 25 35 years. ${ }^{17}$ Precancerous cervical abnormalities take time to develop and a long period of HPV infection. ${ }^{11,22}$ This finding is inconsistent with studies conducted elsewhere. $^{23-26}$ 
Table 4 Multivariate logistic regression analysis showing factors associated with precancerous lesions of the cervix

\begin{tabular}{|c|c|c|c|c|c|}
\hline & VIA result & & & & \\
\hline & Positive & Negative & COR (95\% Cl) & AOR (95\% Cl) & $\boldsymbol{P}$ \\
\hline \multicolumn{6}{|l|}{ Age, years } \\
\hline $25-35$ & $10(6.1 \%)$ & I54 (93.9\%) & 1 & 1 & 1 \\
\hline $36-45$ & $16(13.7 \%)$ & 101 (86.3\%) & $2.13(0.91-4.98)$ & $2.5(0.972-6.63)$ & 0.057 \\
\hline $46-55$ & $16(41 \%)$ & $23(59 \%)$ & $|I .4|$ (4.6I-28.29) & $3.8(1.21-12.47)$ & $0.022 *$ \\
\hline $56-65$ & $10(59 \%)$ & $10(50 \%)$ & $31.40(9.74-101.17)$ & $12.26(3.18-47.18)$ & $0^{*}$ \\
\hline \multicolumn{6}{|l|}{ Residence } \\
\hline Urban & $23(11.4 \%)$ & 178 (88.6\%) & I & I & $\mathrm{I}$ \\
\hline Rural & 29 (20.9\%) & $110(79.1 \%)$ & $2.04(1.12-3.70)$ & $3.524(1.25-9.88)$ & $0.017^{*}$ \\
\hline \multicolumn{6}{|l|}{ Education } \\
\hline None & 34 (25.2\%) & $101(74.8 \%)$ & $0.482(0.23-0.99)$ & $5.19(0.04-632.37)$ & 0.502 \\
\hline Primary ( $1-8$ years) & $12(14 \%)$ & $74(86 \%)$ & $0.178(0.05-0.61)$ & $1.09(0.009-139.88)$ & 0.97 \\
\hline Secondary (9-12 years) & $3(5.7 \%)$ & 50 (94.3\%) & $0.14(0.04-0.48)$ & $5.19(0.04-632.37)$ & 0.5 \\
\hline Diploma and above & $3(4.5 \%)$ & $63(95.5 \%)$ & I & I & 1 \\
\hline \multicolumn{6}{|c|}{ Type of contraceptive used } \\
\hline IUD & $2(7.7 \%)$ & $24(92.3 \%)$ & 1 & 1 & 1 \\
\hline Implant & $3(4.8 \%)$ & 60 (95.2\%) & $0.60(0.09-3.81)$ & $0.46(0.069-3.11)$ & 0.42 \\
\hline Injectable & $6(6.5 \%)$ & $86(93.5 \%)$ & $0.83(0.15-4.4 I)$ & $0.507(0.085-3.02)$ & 0.45 \\
\hline Pills & $28(58.3 \%)$ & $23(41.7 \%)$ & 18.60 (3.95-87.47) & $9.11(1.14-72.8)$ & $0.03 *$ \\
\hline \multicolumn{6}{|c|}{ Age at first intercourse, years } \\
\hline$<18$ & 49 (21.1\%) & $183(78.9 \%)$ & I & I & I \\
\hline$\geq 18$ & $3(2.8 \%)$ & 105 (97.2\%) & $0.107(0.032-0.35 I)$ & $0.009(0-7.53)$ & 0.169 \\
\hline \multicolumn{6}{|l|}{ Parous } \\
\hline No & $2(2.9 \%)$ & $66(97.1 \%)$ & I & I & 1 \\
\hline Yes & $50(18.4 \%)$ & $222(81.6 \%)$ & $7.43(1.76-31.36)$ & I.7I (0.148-19.84) & 0.666 \\
\hline \multicolumn{6}{|l|}{ Age of first birth, years } \\
\hline$<18$ & $34(37.3 \%)$ & $57(62.7 \%)$ & I & I & I \\
\hline$\geq 18$ & $18(9.9 \%)$ & $163(90.1 \%)$ & $0.19(0.10-0.36)$ & $0.42(0.16-1.13)$ & 0.089 \\
\hline \multicolumn{6}{|l|}{ Number of births } \\
\hline$<2$ & $6(14.6 \%)$ & $35(85.4 \%)$ & 1 & 1 & 1 \\
\hline$\geq 2$ & $43(18.6 \%)$ & $188(8 \mid .4 \%)$ & I.845 (0.89-3.80) & $0.543(0.1 \mid 7-2.51)$ & 0.43 \\
\hline \multicolumn{6}{|l|}{ Abortions } \\
\hline No & 27 (11.1\%) & $216(88.9 \%)$ & 1 & I & 1 \\
\hline Yes & $25(25.8 \%)$ & 72 (74.2\%) & $2.77(1.51-5.09)$ & $1.50(0.66-3.42)$ & 0.326 \\
\hline \multicolumn{6}{|l|}{ History of pelvic infection } \\
\hline No & $26(11.5 \%)$ & $200(88.5 \%)$ & 1 & 1 & I \\
\hline Yes & $26(22.8 \%)$ & $88(77.2 \%)$ & $2.27(1.24-4.13)$ & $4.46(0.86-22.92)$ & 0.073 \\
\hline \multicolumn{6}{|l|}{ Women's history of STI } \\
\hline No & $23(6.8 \%)$ & $211(62.1 \%)$ & 1 & I & 1 \\
\hline Yes & $29(8.5 \%)$ & 77 (22.6\%) & $3.45(1.88-6.33)$ & $3.40(1.32-8.78)$ & $0.01 *$ \\
\hline \multicolumn{6}{|l|}{ Partner's history of STI } \\
\hline No & 27 (I2\%) & 198 (88\%) & 1 & 1 & 1 \\
\hline Yes & $25(21.7 \%)$ & 90 (78.3\%) & $2.03(1.12-3.70)$ & $1.3(0.165-10.30)$ & 0.8 \\
\hline \multicolumn{6}{|l|}{ HIV serostatus } \\
\hline Negative & 21 (11.1\%) & $189(89.9 \%)$ & 1 & 1 & I \\
\hline Positive & $25(46.3 \%)$ & $29(53.7 \%)$ & $6.93(3.42-14.04)$ & $4.89(1.54-15.49)$ & $0.007^{*}$ \\
\hline Unknown & $6(7.8 \%)$ & 70 (92.2\%) & $0.64(0.08-5.14)$ & $0.46(0.22-9.61)$ & 0.61 \\
\hline \multicolumn{6}{|c|}{ Number of sexual partners of the women } \\
\hline$<2$ & $6(3.5 \%)$ & $163(96.5 \%)$ & 1 & I & 1 \\
\hline$\geq 2$ & $46(26.9 \%)$ & $125(73.1 \%)$ & $9.95(4.11-24.56)$ & $9.87(1.38-70.4)$ & $0.02 *$ \\
\hline
\end{tabular}

Notes: $* P<0.05 ;$ I, reference. 
A very recent study published in Advances in Public Health revealed that in southern Ethiopia, subjects' education was found to have a significant contribution to the induction of precancerous lesions of the cervix. ${ }^{12}$ Higher educational and better information and knowledge about cervical cancer screening and disease consequencesincreases health-seeking behavior, eg, accessing screening services. ${ }^{27}$ However, in the present study, education was not significantly associated with precancerous cervical lesions of the cervix. This discrepancy may be due to the sample size or methodological differences.

The present study also found that women from rural areas were 2.04 times as likely to develop precancerous cervical lesions as urban dwellers. This finding is similar to a study done in India. ${ }^{28}$ In rural areas, financial and transportation problems may hinder access to hospitals for cervical cancer screening. Women living rurally have lower access to information about cervical cancer and screening services. ${ }^{29}$ Studies in Jamaica, Kenya, and Debre Markos have shown that extended use of oral contraceptives is significantly associated with precancerous cervical lesions. $^{28,30-32}$ Similarly, in our study, women who had used oral contraception were 9.1 times as likely to develop precancerous cervical lesions as IUD users. Prolonged use of oral contraception may increase eversion of the columnar epithelium to the ectocervix, which enhances the exposure of the columnar epithelium to HPV infection. ${ }^{33}$

Mean age of first sexual intercourse for the study participants was 17.03 , close to mean age at first marriage -16.99 years. This suggests that women generally begin sexual intercourse at the time of their first marriage. About 232 (68.2\%) respondents had their first sexual intercourse aged $<18$ years; however, there was no significant association between age at first sex and precancerous cervical lesions. Our finding contradict other studies done in different settings, ${ }^{12,34-37}$ which showed that early initiation of sexual intercourse was significantly associated with developing precancerous cervical lesions. This discrepancy may be due to failure to remember age at first sex.

Women with a history of STI were 3.4 times as likely to have precancerous cervical lesions as those with no such history, similar to other studies. ${ }^{24,38-41}$ This association might be because of coinfections of HPV with other STIs. In this study, those women (15.9\%) were HIVpositive. Women who had HIV-positive serostatus were 4.8 times as likely to have precancerous cervical lesions as HIV-negatives. Moreover, this high prevalence of precancerous cervical cancer lesions reveals that cervical cancer is a significant public health problem among HIVinfected women, though the prevalence of precancerous cervical cancer in uninfected women is unknown in the study setting. Our finding is strongly supported by studies done in Tanzania, ${ }^{20}$ Uganda, ${ }^{38}$ southern Ethiopia, ${ }^{12}$ and Amhara in northwest Ethiopia. ${ }^{36}$ HIV infection is an immuno-suppressive disease that increases the likelihood of concurrent HPV infection. ${ }^{42}$ A very recent study in southern Ethiopia showed that women with multiple sexual partners had 40 times the odds of cervical cancer of those with no multiple sexual partners. ${ }^{12}$ In the current study, a history of multiple sexual partners had a statistically significant effect on the existence of precancerous lesions of the cervix. Moreover, our findings are also in line with other studies. ${ }^{15,25,32,37,41,43}$ Having multiple sexual partners increases the likelihood of acquiring HPV infection and in turn cervical cancer.

\section{Conclusion}

The present study identified relatively high prevalence of precancerous cervical lesions (15.3\%) among women screened for cervical cancer. Those aged 46-65 years had a higher risk of precancerous cervical lesions than those aged 25-35 years. Women with prolonged use of oral contraception were more at risk of developing precancerous cervical lesions than IUD users. Women with a history of postcoital bleeding, STI, multiple sexual partners, and who were HIV-positive had an increased risk of precancerous cervical lesions. Therefore, outreach cervical cancer-screening services are needed to get more women in for screening, as well as encouraging all women aged above 46 years and a history of STI, HIV, and multiple sexual partners to be screened for cervical cancer. Women who need to use family-planning methods should use long-term methods like IUDs and implants. There is also a need to design strong policies and guidelines on the prevention and control of precancerous lesions of the cervix.

\section{Abbreviations}

$\mathrm{CIN}$, cervical intraepithelial neoplasia; HPV, human papillomavirus; IUD, intrauterine device; SCJ, squamocolumnar junction; STI, sexually transmitted infection; VIA, visual inspection with acetic acid. 


\section{Data Sharing}

The data used to support the findings of this study are available from the corresponding author upon request.

\section{Acknowledgments}

We would like to thank the University of Gondar College of Medicine and Health Sciences for giving ethics approval to start the study. Our eep appreciation goes to the hospital managers for their permission. We would also like to thank the study participants for their time and the data collectors and supervisors for their commitment.

\section{Author Contributions}

All authors made substantial contributions to conception and design, acquisition of data, or analysis and interpretation of data, took part in drafting the article or revising it critically for important intellectual content, agreed to submit to the current journal, gave final approval to the version to be published, and agree to be accountable for all aspects of the work.

\section{Disclosure}

The authors declare that they have no competing interests regarding the publication of the paper.

\section{References}

1. Ludmir J, Sehdev HM. Anatomy and physiology of the uterine cervix. Clin Obstet Gynecol. 2000;43(3):433-439. doi:10.1097/ 00003081-200009000-00003

2. Mukonoweshuro P, Oriowolo A, Smith M. Audit of the histological definition of cervical transformation zone. J Clin Pathol. 2005;58 (6):671.

3. Chigira M, Noda K, Watanabe H. Autonomy in tumor cell proliferation. Med Hypotheses. 1990;32(4):249-254. doi:10.1016/ 0306-9877(90)90101-J

4. Berek JS; Berek \& Novak's Gynecology. Cervical and Vaginal Cancer. 14th ed. USA: Lippincott Williams \& Wilkins; 2007.

5. Sharma K, Dubey S, Vyas S. Histopathological spectrum of cervical lesions in a tertiary health care centre. Significance. 2010;14(1):0-001.

6. Zhang T, Luo YM, Li P, et al. Cervical precancerous lesions classification using pre-trained densely connected convolutional networks with colposcopy images. Biomed Signal Process Control. 2020;55:101566. doi:10.1016/j.bspc.2019.101566

7. Federal ministry of health Ethiopia. Cervical cancer treatment and prevention guidelines; 2015.

8. Arbyn M, Weiderpass E, Bruni L, et al. Estimates of incidence and mortality of cervical cancer in 2018: a worldwide analysis. Lancet Global Health. 2020;8(2):e191-e203. doi:10.1016/S2214-109X(19) 30482-6

9. Nogara PRB, Manfroni LAR, da Silva MC, Consolaro MEL. The "see and treat" strategy for identifying cytologic high-grade precancerous cervical lesions among low-income Brazilian women. Int $J$ Gynecol Obstet. 2012;118(2):103-106. doi:10.1016/j.ijgo.2012.02.017

10. Gebremariam T. Human papillomavirus related cervical cancer and anticipated vaccination challenges in Ethiopia. Int $J$ Health Sci. 2016;10(1):137. doi:10.12816/0031220
11. Bruni LAG, Serrano B, Mena M, et al. Human papillomavirus and related diseases in Ethiopia. Summary Report ICO/IARC Information Centre on HPVand Cancer (HPV Information Centre). 2019.

12. Teka T, Kote M, Kejela G, Getachew T. Magnitude and factors associated with precervical cancer among screened women in Southern Ethiopia. Adv Public Health. 2019;2019:1-8. doi:10.1155/ 2019/5049752

13. de Sanjosé S, Serrano B, Castellsagué X, et al. Human papillomavirus (HPV) and related cancers in the global alliance for vaccines and immunization (GAVI) countries: a WHO/ICO HPV information centre report. A WHO/ICO HPV Information Centre Report; 2012.

14. Federal Democratic Republic of Ethiopia Ministry of Health. Health Sector Development Programme IV 2010/11 - 2014/15; 2010.

15. Abate M, Dilnessa T, Workie A, Temesgen K. Proportions of PreCancerous Cervical Lesions and Its Associated Factors among Women Clients in the Age Group of 30-49yrs in Gynecology Ward of Dessie Referral Hospital and FGAE, North-East Ethiopia, 2016. $J$ Cancer Tumor Int. 2019;1-15. doi:10.9734/jcti/2019/v9i230105

16. Kahesa C, Kjaer SK, Ngoma T, et al. Risk factors for VIA positivity and determinants of screening attendances in Dar es Salaam, Tanzania. BMC Public Health. 2012;12(1):1055. doi:10.1186/14712458-12-1055

17. Tao L, Han L, Li X, et al. Prevalence and risk factors for cervical neoplasia: a cervical cancer screening program in Beijing. $B M C$ Public Health. 2014;14(1):1185. doi:10.1186/1471-2458-14-1185

18. Derbie A, Mekonnen D, Mezgebu Y, Biadglegne F. Cervical lesion detection using visual inspection with acetic acid and associated factors among ethiopian women. Ethiop Med J. 2019;2:57.

19. African Population and Health Research Center, International Agency for Research on Cancer, World Health Organization. Prevention of cervical cancer through screening using visual inspection with acetic acid (VIA) and treatment with cryotherapy. A demonstration project in six African countries: Malawi, Madagascar, Nigeria, Uganda, the United Republic of Tanzania, and Zambia. Geneva: World Health Organization; 2012.

20. Chambuso RS, Shadrack S, Lidenge SJ, Mwakibete N, Medeiros RM. Influence of HIV/AIDS on cervical cancer: a retrospective study from Tanzania. J Glob Oncol. 2017;3 (1):72-78. doi:10.1200/JGO.2015.002964

21. Gedefaw A, Astatkie A, Tessema GA. The prevalence of precancerous cervical cancer lesion among HIV-infected women in Southern Ethiopia: a cross-sectional study. PLoS One. 2013;8:e84519.

22. Tesfa A. Combating cervical cancer in Ethiopia. Pathfinder International/Ethiopia; 2010.

23. Zekariase G, Zemen T, Mussie Aet al. Determinant factors of visual inspection with acetic acid (via) positive lesions among hiv positive women in Mekelle hospital, Northern Ethiopia: a case control study. Ethiop Med J. 2015;53:17-24.

24. Belayneh T, Mitiku H, Weldegebreal F. Precancerous cervical lesion and associated factors among HIV-infected women on ART in Amhara Regional State, Ethiopia: a hospital-based cross-sectional study. Int J Health Sci. 2019;13(3):4.

25. Teame H, Addissie A, Ayele W, et al. Factors associated with cervical precancerous lesions among women screened for cervical cancer in Addis Ababa, Ethiopia: a case control study. PLoS One. 2018;13(1): e0191506. doi:10.1371/journal.pone.0191506

26. Bezabih M, Tessema F, Sengi H, Deribew A. Risk factors associated with invasive cervical carcinoma among women attending Jimma University specialized hospital, Southwest Ethiopia: a case control study. Ethiop J Health Sci. 2015;25(4):345. doi:10.4314/ejhs.v25i4.8

27. Brinton LA, Fraumeni JF. Epidemiology of uterine cervical cancer. J Chronic Dis. 1986;39(12):1051-1065. doi:10.1016/0021-9681(86) 90139-6

28. Fotra R, Gupta SH, Gupta S. Sociodemographic risk factors for cervical cancer in Jammu region of Jand $\mathrm{K}$ state of India first ever report from Jammu. Indian J Sci Res. 2014;9(1):105. 
29. Mupepi SC, Sampselle CM, Johnson TR. Knowledge, attitudes, and demographic factors influencing cervical cancer screening behavior of Zimbabwean women. J Women's Health. 2011;20(6):943-952. doi:10.1089/jwh.2010.2062

30. Huchko MJ, Leslie H, Sneden J, et al. Risk factors for cervical precancer detection among previously unscreened HIV-infected women in Western Kenya. Int J Cancer. 2014;134(3):740-745. doi:10.1002/ijc.28401

31. Getinet M, Gelaw B, Sisay A, Mahmoud EA, Assefa A. Prevalence and predictors of Pap smear cervical epithelial cell abnormality among HIV-positive and negative women attending gynecological examination in cervical cancer screening center at Debre Markos referral hospital, East Gojjam, Northwest Ethiopia. BMC Clin Pathol. 2015;15(1):16. doi:10.1186/s12907-015-0016-2

32. McFarlane-Anderson N, Bazuaye PE, Jackson MD, Smikle M, Fletcher HM. Cervical dysplasia and cancer and the use of hormonal contraceptives in Jamaican women. BMC Women's Health. 2008;8 (1):9. doi:10.1186/1472-6874-8-9

33. Bright PL, Norris Turner A, Morrison CS, et al. Hormonal contraception and area of cervical ectopy: a longitudinal assessment. Contraception. 2011;84(5):512-519. doi:10.1016/j.contraception.20 11.02 .002

34. Beyene TT, Akibu M, Bekele H, Seyoum W. Determinants of precancerous cervical lesion among women screened for cervical cancer in south Ethiopia: a case-control study. Res Sq. 2019. doi:10.21203/ rs. $2.14781 / \mathrm{v} 1$

35. Ansa M, Mekonnen T. Prevalence of via positive cervical lesions and determinant factors among women attending regular gynecology outpatient department (rgopd) at Saint Paul's hospital millennium medical college (sphmmc). Ethiop J Reprod Health. 2018;10:11.
36. Kassa LS, Dile WM, Zenebe GK, Berta AM. Precancerous lesions of cervix among women infected with HIV in Referral Hospitals of Amhara Region, Northwest Ethiopia: a cross sectional study. Afr Health Sci. 2019;19(1):1695-1704. doi:10.4314/ahs.v19i1.46

37. Utoo B, Utoo P, Ngwan S, Anzaku S, Daniel M. Cervical intraepithelial neoplasia: prevalence, risk factors, and utilization of screening services among an urban population in Nigeria. Trop J Obstet Gynaecol. 2016;33(3):279. doi:10.4103/0189-5117.199810

38. Izudi J, Adrawa N, Amongin D. Precancerous cervix in human immunodeficiency virus infected women thirty years old and above in Northern Uganda. J Oncol. 2016;2016:1-7. doi:10.1155/2016/ 5473681

39. Chichareon S, Herrero R, Munoz N, et al. Risk factors for cervical cancer in Thailand: a case-control study. J Natl Cancer Inst. 1998;90 (1):50-57. doi:10.1093/jnci/90.1.50

40. Plisko O, Zodzika J, Rezeberga D, et al. Associations between sexually transmitted infections and cervical precancerous lesions in Latvian women. Eur J Obstet Gynecol Reprod Biol. 2019;234:e153. doi:10.1016/j.ejogrb.2018.08.493

41. Temmerman M, Tyndall M, Kidula N, Claeys P, Muchiri L, Quint W. Risk factors for human papillomavirus and cervical precancerous lesions, and the role of concurrent HIV-1 infection. Int J Gynecol Obstet. 1999;65(2):171-181. doi:10.1016/S0020-7292(99)00043-0

42. Moodley JR, Hoffman M, Carrara H, et al. HIV and pre-neoplastic and neoplastic lesions of the cervix in South Africa: a case-control study. BMC Cancer. 2006;6(1):135. doi:10.1186/1471-2407-6-135

43. Bosch FX, Manos MM, Muñoz N, et al. Prevalence of human papillomavirus in cervical cancer: a worldwide perspective. $J$ Natl Cancer Inst. 1995;87(11):796-802. doi:10.1093/jnci/87.11.796

\section{Publish your work in this journal}

Cancer Management and Research is an international, peer-reviewed open access journal focusing on cancer research and the optimal use of preventative and integrated treatment interventions to achieve improved outcomes, enhanced survival and quality of life for the cancer patient.
The manuscript management system is completely online and includes a very quick and fair peer-review system, which is all easy to use. Visit http://www.dovepress.com/testimonials.php to read real quotes from published authors. 